\title{
A COUPLED NUMERICAL MODELLING AND EXPERIMENTAL APPROACH IN CHEMICAL VAPOUR INFILTRATION (CVI) PROCESS OF SiC/SiC COMPOSITES
}

\author{
E. SCHNACK ${ }^{1}$, A. $\mathrm{LI}^{2}$, A.M. RAHMAN ${ }^{1} \&$ Y. ZHU ${ }^{3}$ \\ ${ }^{1}$ Institute of Engineering Mechanics, Karlsruhe Institute of Technology (KIT), Germany. \\ ${ }^{2}$ Research Centre for Composite Materials (RCCM), Shanghai University (SHU), China. \\ ${ }^{3}$ Division of Solid Mechanics, Lund University, Sweden.
}

\begin{abstract}
Fabrication of silicon carbide fibres reinforced silicon carbide composite $(\mathrm{SiC} / \mathrm{SiC})$ by chemical vapour infiltration (CVI) process was investigated in this research with the help of both simulation and experimental set-up. CVI of silicon carbide preform was carried out through the pyrolysis of methyltrichlorosilane (MTS) over a broad temperature range at atmospheric pressure. The overall aim was the morphological description of the matrix (co-deposition of $\mathrm{Si}, \mathrm{SiC}$ and $\mathrm{C}$ ) during pyrolysis of MTS by CVI process and its state-of-the-art numerical calculation. Phase-field model was developed and deployed to predict the evolution of the microstructures and to describe the influence of the infiltration conditions on the properties of the composite during CVI process in conjunction with the implication of finite element method. Both mass transport and fluid motion in gas phase were considered. Experimental results exhibit three deposition regimes at different temperature ranges as predicted by the numerical simulation results. This also implies different deposition kinetics involved as investigated in the present research. The great difference of the steady-state deposition rate exceeding three orders of magnitude was explained in terms of a multiple steady-state surface reaction model of co-deposition of $\mathrm{SiC}, \mathrm{Si}$ and C. Corresponding gas-phase compositions, over the temperature region covered in the present experiments, were calculated with a detailed pyrolysis reaction mechanism of MTS.
\end{abstract}

Keywords: chemical engineering, chemical vapour infiltration, composite, phase field, simulation.

\section{INTRODUCTION}

Silicon carbide fibre reinforced silicon carbide matrix composite ( $\mathrm{SiC} / \mathrm{SiC}$ composite) has attracted increasing attention in the industrial applications because of their useful properties such as improved fracture toughness, resistance to abrasion and light weight [1,2]. They are widely used in the space industries, in defence industry as bullet proof vest, in automotive industries as break disk and many more to mention [3-8]. Large-scale production of $\mathrm{SiC} / \mathrm{SiC}$ composite is still restricted by its production cost. One of the ways to reduce the production cost without compromising the quality is chemical vapour infiltration (CVI) [9-11] process, a special form of widely known chemical vapour deposition (CVD). In this particular process, a thin solid film is synthesized from the gaseous phases by chemical reactions at elevated temperature to form fibre-reinforced composites [12]. It is this reactive process that differentiates CVD from physical deposition processes, such as evaporation, sputtering and sublimation. During this process, fibrous preform is supported on a porous metallic plate through which a mixture of carrier gas along with matrix material is passed at an elevated temperature. Preforms can be made of yarns, woven fabrics, filament wound or braided three-dimensional (3D) shapes [13]. The infiltration process takes place in a reactor which is connected to an effluent treatment plant where the gases and residual matrix material are chemically treated. In this process, the residual stresses of the structure are lower due to lower infiltration temperature, and complex large shapes can be produced in a cost-effective way with minimum damage to the fibre preform [14]. The composites prepared by this method 
have enhanced mechanical properties, corrosion resistance and thermal shock resistance. Various matrices and fibre combinations can be used to produce different composites such as $\mathrm{SiC}, \mathrm{C}, \mathrm{Si}_{3} \mathrm{~N}_{4}, \mathrm{BN}, \mathrm{B}_{4} \mathrm{C}, \mathrm{ZrC}$, etc. and thereby allow considerable flexibility in selecting fibres and matrices. Very pure and uniform matrix can be obtained by carefully controlling the purity of these gases. To strictly control the morphology and porosity of SiC film, CVI methods with isothermal and isobaric conditions were explored, where both reactant concentrations and reaction rates remain constant, theoretically, during the whole process [14]. It is worth to mention that CVI is now considered as one of the most important methods of $\mathrm{SiC} /$ $\mathrm{SiC}$ composite production in large scale. During this process, $\mathrm{SiC}$ matrix is deposited on the porous $\mathrm{SiC}$ preform by pyrolysis of methyltrichlorosilane $\left(\mathrm{CH}_{3} \mathrm{SiCl}_{3}\right)$ commonly abbreviated as MTS. MTS has high deposition rate, over $110 \mu \mathrm{m} / \mathrm{h}$ [15]. In addition, it acts as SiC precursor, providing both carbon and silicon to the gas mixture. However, the $\mathrm{C} / \mathrm{Si}$ ratio will be fixed at 1 , if only MTS is used as the precursor. Therefore, to adjust the C/Si ratio, which has been proved to be an important way of controlling the morphology and the amount of impurities in the composite structure, $\mathrm{H}_{2}$ was used as the carrier gas [16]. This process obviously involves the complicated interactions among gaseous flow, mass/heat transport phenomena as well as chemical reactions. Usually, CVI process suffers from non-uniform densification and high residual void fraction (porosity) in the overall composite structure. To address these issues, measures were taken to ensure that mass transport rates are higher than that of deposition rates during the process. These take extremely long process times, up to several weeks in some cases, and hence, make the experimental investigation very difficult, while simulation provides an alternative solution. Therefore, the most important challenge is finding the optimal technological parameters followed by verification of the simulation results by experimental set-up, with the best-fit process parameters. An examination of the available literature shows that there are large numbers of publications on CVI modelling [17]; however, most of the papers generally described 1D model to account the phenomena occurring inside the preform without considering the transport processes in the whole reactor system. Therefore, the objective of the present research is twofold: (i) to model and simulate $\mathrm{SiC} / \mathrm{SiC}$ composite manufacturing through CVI process in a 3D model to overcome the current limitations as stated before and (ii) verification of the simulation results with experimental data. The overall goal is to achieve the morphological description of the matrix (co-deposition of $\mathrm{Si}, \mathrm{SiC}$ and C) during the process and its state-of-the-art numerical calculation. The research is expected to improve our understanding on microstructural evolution of $\mathrm{SiC} / \mathrm{SiC}$ composite under different process parameters.

\section{EXPERIMENTAL}

The schematic of the deposition apparatus and the reactor flow chart are shown in Fig. 1. The gases were taken from gas cylinders under controlled flow rates regulated by mass flow meters (MFC). A fraction of hydrogen was flowing through an evaporator for the uptake of MTS. Concentrations of vapours are made by bubbling the carrier gas $\left(\mathrm{H}_{2}\right.$ in this case). This method requires optimum pressure and temperature control of the bubbler system. In the present work, hydrogen was used not only as a dilution/carrier gas to transport the reactants to the hot surface but also as a reactant for the chemical reaction to form $\mathrm{SiC}$ and to remove organic contaminations on the substrate surface immediately before the film deposition. After flowing through the reactor, the exhaust stream passes a post-processing system to get rid of most hazard composition and then the left was output by an electronically controlled membrane pump. The experiments were performed under atmospheric pressure, measured at the 


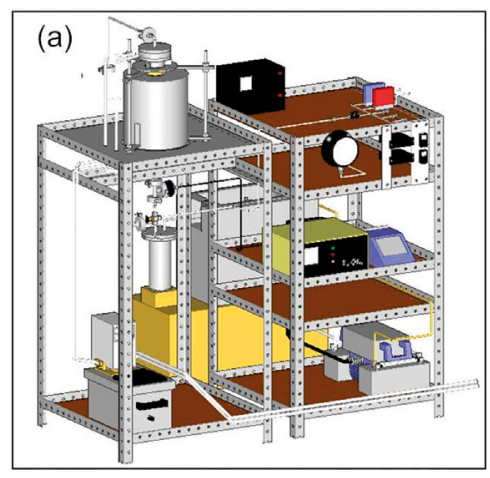

(b)

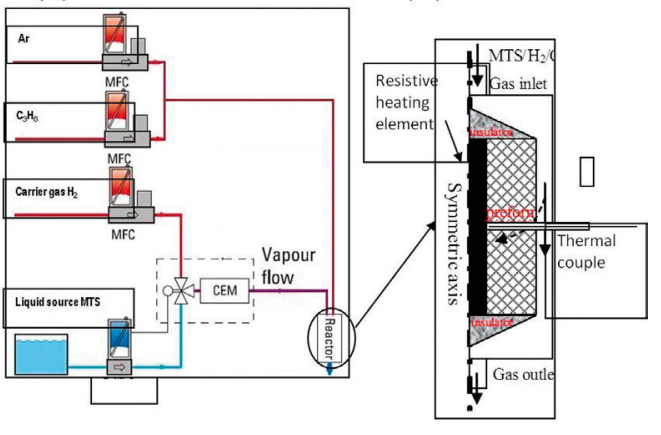

Figure 1: Schematic of the deposition apparatus (a), the reactor flow chart (b) and the reactor (c).

entrance of the reactor. The liquid source, MTS was taken from a container and flows through the L-MFC. MTS and $\mathrm{H}_{2}$ flowing through a three-way valve were mixed in the controlled evaporation system (CEM) for the uptake of MTS. The CEM system offers an optimum pressure and temperature control of the liquid source.

Graphite-resistive heating elements were placed in the centre of the reactor, as shown in Fig. 1c. The gas-phase precursor enters the reaction chamber from above and exits from below with a high flow rate, which leads to a convective freshening of the outer surface of the preform, a distinct temperature gradient within the preform and in the gap existing between the preform and the reactor wall. As pure $\mathrm{SiC}$ matrix could be formed only at higher temperatures, normally above $1050^{\circ} \mathrm{C}$, the temperature of the graphite-resistive heating element was set at $1100^{\circ} \mathrm{C}[18,19]$.

In the reactor, a $\mathrm{SiC}$ fibre felt preform with a fibre volume fraction of $30 \%$ was used. The diameter of SiC fibre was approximately $12 \mu \mathrm{m}$ and the equivalent diameter of pore was approximately $24 \mu \mathrm{m}$. Conical inlet and outlet nozzles were connected to the deposition space to reduce pre-decomposition of MTS. Prior to $\mathrm{SiC}$ deposition, the substrate was coated with pyrolytic carbon using $\mathrm{C}_{3} \mathrm{H}_{8} / \mathrm{CH}_{4}$ as precursor at $1000-1100^{\circ} \mathrm{C}$ for several hours in order to fill-up the porous surface. Since the pre-coated pyrolytic carbon exhibits similar thermal expansion coefficient to that of $\mathrm{SiC}$, it is beneficial for the formation of thick $\mathrm{SiC}$ coatings without cracks.

\section{MULTIPHASE FIELD MODEL OF THE CVI PROCESS}

Growth mechanism description of $\mathrm{SiC} / \mathrm{SiC}$ composite during CVI processing through an accurate mathematical model is extremely complex [20], as the time and length scales where chemical and physical processes take place differ by several orders of magnitude: from macro-scale through meso-scale and micro-scale towards atomic scale. A macro-scale model is frequently adopted if the scope of the modelling is the optimization of the film growth rate and its profile. A meso-scale model is used when the interest is towards the study of the filling between the pores. A micro-scale modelling can aid to investigate the film morphological evolution, while atomistic models are usually used to examine the surface and gas-phase chemistry. Kulik et al. [21] considered a 2D model of CVI process and used for the simulation of CVI by analysing flow patterns, thermal field and distributions of species concentrations 
in the fibrous preform and in the gas region of the reactor. Though CVI modelling has reached rather a mature stage, fully integrated multiscale approaches are not yet well developed as evident in various review papers [21,22]. A multiscale model should intend to deal simultaneously with all the scales recognized in the CVI process, such as: (1) a macroscopic scale (the whole reactor cavity and the perform, considered as a homogeneous medium), (2) one or more scales related in detail to the pore space (their dimensions depend on the type of preform and fabrication methods) and (3) eventually a 'atomic' scale referring to the dimension of the atoms/molecules and the species reagent between each other and with the substrate. Vignoles et al. [22] proposed a global scheme and obtained a unique modelling tool to be used for the predictions and infiltration process parameter optimization. Three critical issues were identified, namely: (1) reaction scheme kinetics, which involve homogeneous and heterogeneous reactions; (2) models of porous media at various densification levels, related to the description of geometry and transfer mechanism and (3) appropriate methods for coupling. By taking into consideration the above-mentioned issues, phase-field method was used in this study to predict the microstructural evolution during the CVI process. It is very important to choose a proper model to simulate the impact of process conditions. Presently two methods, namely (i) the sharp interface model and (ii) the Eulerian techniques are often adopted. Though they enjoy great popularity, each of them has their own cons. For sharp interface model, it is difficult to precisely track the interface. While Eulerian techniques lack the complete conservation of mass and volume-fluid methods when calculating the interface curvature from volume fractions, phase-field model utilize a diffusive region instead of a sharp interface to describe the interface difference between gas and solid phase. As the parameter varies from one phase to another continuously, this model is pretty suitable for the motion interface depending on the external field normal to the interface and the regional curvature of the interface. Some scientist has proved that the solution of phase-field model converges to the results of corresponding sharp interface model when the thickness of the interface approaches zero [23]. In this work, we aim to build a phase-field model specific for CVI process to describe the evolution of the $\mathrm{SiC} / \mathrm{SiC}$ composite microstructure.

Compared with other meso-scale methods, the phase-field model is capable of avoiding the explicit tracking of the interface and the complicated re-meshing of the computational domain in the moving boundary problem. It assembles many features of level-set method but avoids the numerical instability through an advection-diffusion equation. The phase-field method is a potential method that can be applied in the different multiphysics field problems by adoption of different system free energy.

\subsection{Thermodynamics and kinetics of CVI process}

During CVI process of $\mathrm{SiC} / \mathrm{SiC}$ composite fabrication, MTS was used as the precursor in the presence of hydrogen $\left(\mathrm{H}_{2}\right)$, which acts as the carrier gas in the reactor. For thermal decomposition of MTS, the reduced mechanism was adopted, which allows a detailed thermodynamics description. Based on the work by Zhang and Hüttinger [24], Allendorf and Melius [25] and Fitzer and Kehr [26], a model of both homogeneous gas-phase chemistry and heterogeneous surface chemistry was presented. Here, $\mathrm{CH}_{3}$ and $\mathrm{C}_{2}$ species were assumed to be the carbon sources, while $\mathrm{SiCl}_{3}$ and $\mathrm{HSiCl}_{3}$ were assumed to be the silicon sources for the deposition of $\mathrm{C}, \mathrm{Si}$ and $\mathrm{SiC}$ and the dissociation reaction of MTS was as follows [27]:

$$
\begin{gathered}
\mathrm{CH}_{3} \mathrm{SiCl}_{3}+\mathrm{H}_{2} \rightleftharpoons \mathrm{SiCl}_{3}+\mathrm{CH}_{3}+\mathrm{H}_{2} \\
\mathrm{CH}_{3}+\mathrm{H}_{2} \rightleftharpoons \mathrm{CH}_{4}+\mathrm{H}
\end{gathered}
$$




$$
\begin{aligned}
& \mathrm{CH}_{3}+\mathrm{CH}_{3} \rightleftharpoons \mathrm{C}_{2} \mathrm{H}_{4}+\mathrm{H}_{2} \\
& \mathrm{SiCl}_{3}+\mathrm{H}_{2} \rightleftharpoons \mathrm{HSiCl}_{3}+\mathrm{H}
\end{aligned}
$$

Formation of the depositions $\left({ }^{*}\right.$ indicates the adsorption of the intermediate species on free surface site):

$$
\begin{aligned}
\mathrm{CH}_{3}{ }^{*}+3 \mathrm{H} & \rightleftharpoons \mathrm{C}^{*}+3 \mathrm{H}_{2} \\
\mathrm{C}_{2} \mathrm{H}_{4}{ }^{*}+4 \mathrm{H} & \rightleftharpoons 3 \mathrm{C}^{*}+4 \mathrm{H}_{2} \\
\mathrm{SiCl}_{3}{ }^{*}+3 \mathrm{H} & \rightleftharpoons \mathrm{Si}^{*}+3 \mathrm{HCl} \\
\mathrm{HSiCl}_{3}{ }^{*}+2 \mathrm{H} & \rightleftharpoons \mathrm{Si}^{*}+3 \mathrm{HCl} \\
\mathrm{Si}^{*}+\mathrm{C}^{*} & \rightleftharpoons \mathrm{SiC}
\end{aligned}
$$

\subsection{Phase-field equation}

As shown in Fig. 2, the gas-solid interface was implicitly denoted by the spatially diffusive phase-field order parameter $(\varphi)$ instead of sharp interface. Therefore, the spatio-temporal behaviour of phase-field order parameter reproduces the deposited SiC microstructure evolution. Multiphase field order parameters were adopted in case of the co-deposition of condensed solid phases $\beta$-SiC(s) with $\mathrm{Si}(\mathrm{s})$ or $\beta$-SiC(s) and $\mathrm{C}$ (graphite) under specific CVI processing conditions. The existence of bulk phase $i$ was represented by phase-field order parameters

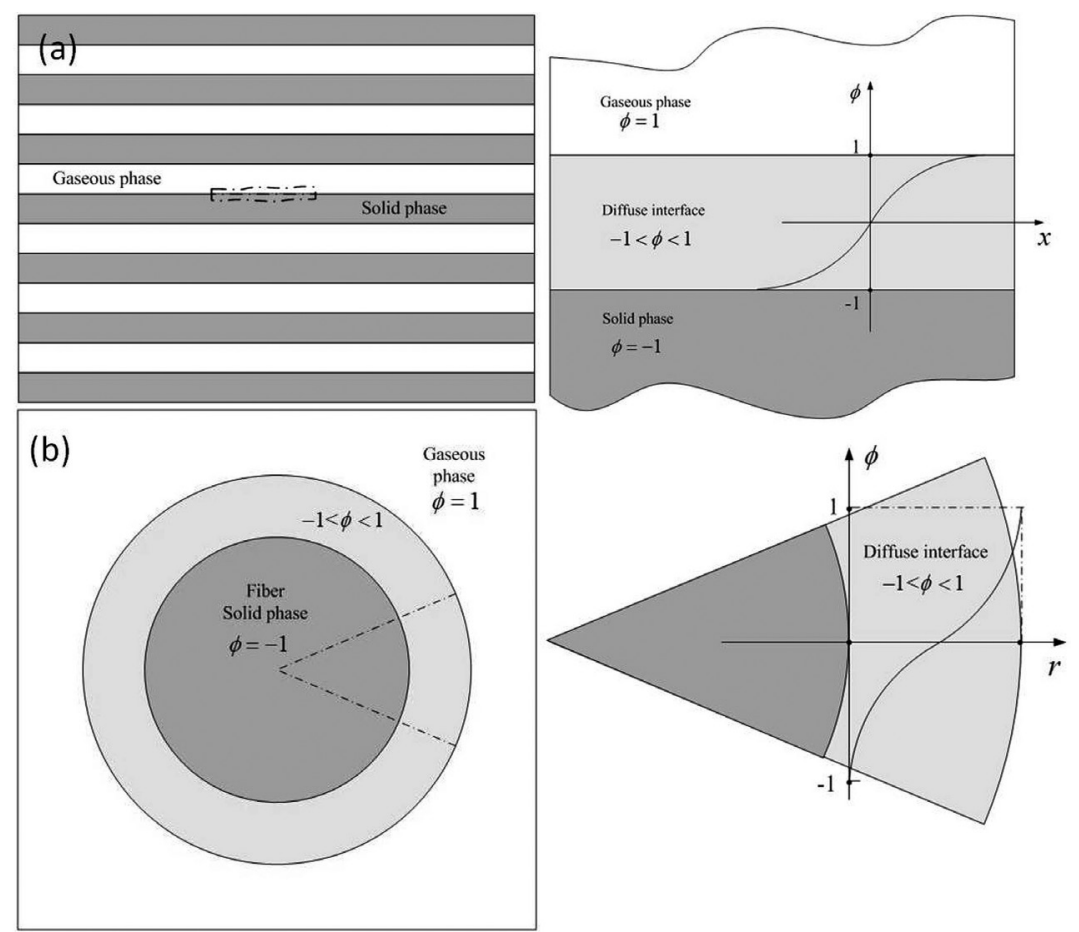

Figure 2: Schematic illustration of the definition of the phase-field parameter $(\varphi)$ : (a) fibre axis and (b) fibre vertical direction [30]. 
( $\varphi_{i}, i=1, \ldots N, N$ is the number of phases) to be 1 , otherwise 0 in the rest phases, and $0<\varphi_{i}$ $<1$ in the interfaces between $i$ th and the other phases.

The sum of these phase-field order parameters should be conserved as [27]:

$$
\sum_{i=1}^{N} \varphi_{i}=1
$$

where $\varphi_{1}$ denotes multicomponent gaseous phase and $\varphi_{2}, \varphi_{3}, \varphi_{4}$ denote silicon, silicon carbide and carbon respectively.

Chemical reactions, as stated in Section 3.1, were governed by thermodynamics and kinetics. The thermodynamics defines the driving force which indicates the potential direction that the reaction would precede. The kinetics defines the transport process and subsequently determines the rate-control step during the process. Both of these two aspects of information should be introduced into the multiphase field model. The free energy changing for a reaction was defined as [27]:

$$
\Delta G_{r}=\sum z^{i} \Delta G_{f, i}^{0}+R T \operatorname{In} Q
$$

where $z^{i}$ is the stoichiometric coefficient of species $i$ in reaction (negative for reactants, positive for products), $R\left(\mathrm{~J} \mathrm{~mol}^{1} \mathrm{~K}^{1}\right)$ the ideal gas constant, $Q$ the reaction quotient which was related to the activity and partial pressure of species $i, G_{f, i}^{0}$ the standard free energy of formation of species $i$ at temperature $T(\mathrm{~K})$ and at 1 atm pressure according to Eqn. (12) [27]:

$$
\Delta G_{f, i}^{0}=\Delta H_{i}+T \Delta S_{i}
$$

where the enthalpies $H$ and the entropies $S$ can be calculated based on JANAF thermochemical tables [28]. The thermodynamics properties of individual substances can be found by referring to Ref. [29].

The Ginzburg-Landau type of system free energy can be expressed as [27]:

$$
F=\int_{\Omega} \sum_{j>i} \sum_{i=1}^{N}\left[-\frac{\epsilon_{i j}^{2}}{2} \nabla \varphi_{i} \nabla \varphi_{j}+W_{i j} \varphi_{i} \varphi_{j}+f_{e}+\lambda_{\mathrm{L}}\left(\sum_{i=1}^{N} \varphi_{i}-1\right)\right] \mathrm{d} \Omega
$$

where $\varepsilon_{i j}$ is the gradient energy coefficient and $W_{i j}$ the height of the energy barrier. $\varepsilon_{i j}$ is dependent on the interface tensor and the interface thickness [31]. Anisotropy of the interface energy was incorporated into the model by the dependence of $\varepsilon_{i j}$ on the orientation $\left(\varphi_{i}, \nabla \varphi_{i}\right)$ [32]. The Lagrange multiplier $\lambda_{\mathrm{L}}$ was introduced to account for the sum of phase field in the system to be conserved. Details of the derivation and interpretation can be found in our previous works $[30,33,34]$. In the following sections, fluid flow, mass and heat transport will be coupled with phase-field order parameters, which account for the interfacial dynamics implicitly.

\subsubsection{Mass transport}

The modified mass transport of the species in the process of CVI can be stated in the compact form of a time-dependent convection-diffusion problem [27]:

$$
\partial_{i} c_{i}=-\varphi_{1}(\boldsymbol{u} \cdot \nabla) c_{i}+\nabla \cdot\left[D \nabla c_{i}\right]+r_{i}^{\mathrm{eff}}, i \in\{\text { gaseous species }\}
$$

where $c_{i}$ is the molar concentration of gaseous species $i, i \in$ indicates that the diffusion of each species in solid phases was disregarded due to its low diffusivity, $u$ the velocity vector 
and $D$ the diffusivity. Details of the derivation and interpretation can be found in our previous works $[30,33,34]$.

\subsubsection{Fluid transport}

A modified Navier-Stokes equation was employed to describe the evolution of the gaseous fluid motion [27]:

$$
\begin{gathered}
\nabla \cdot\left(\varphi_{1} \boldsymbol{u}\right)=0 \\
\rho \frac{\partial\left(\varphi_{1} \boldsymbol{u}\right)}{\partial t}=-\rho\left(\varphi_{1} \boldsymbol{u} \cdot \nabla\right) \boldsymbol{u}+\varphi \nabla \cdot(-p) I+\eta \nabla \cdot\left[\nabla\left(\varphi_{1} \boldsymbol{u}\right)+\left(\nabla\left(\varphi_{1} \boldsymbol{u}\right)\right)^{T}\right]+B \eta\left(\varphi_{1}^{2}\left(1-\varphi_{1}\right) \boldsymbol{u}\right)
\end{gathered}
$$

where $\boldsymbol{u}$ is the velocity, the density (the same density assumed for different gaseous species for simplicity), $\eta$ the viscosity, $I$ the unit metric, $T$ the inversion sign and $B$ the parameter depending on the gradient energy coefficient $\varepsilon$. The last term in eqn. (16) was the force term, which was chosen such that 'no-slip' condition can be accurately reproduced regardless of the diffusive interface thickness [35]. Details of the derivation and interpretation can be found in our previous works $[30,33,34]$.

\subsubsection{Heat transport}

Heat transport plays a key role in the case of thermal gradient process (TGCVI). The vapour precursor diffuses through the preform from the cool side to the hot regions. Both gas diffusion and chemical reaction rate in high temperature region were greatly enhanced. The uniform formulation of heat balance can be applied for both solid and gas phase in the whole domain except that heat convection should be included in gas phase as a fluid. The following heat convection and conduction equation was used [27]:

$$
\rho C_{p} \frac{\partial T}{\partial t}+\nabla \cdot(-k \nabla T)+\rho C_{p} \varphi_{1} \boldsymbol{u} \cdot \nabla T-Q=0
$$

where $T$ is the temperature, $\boldsymbol{u}$ the velocity, the density, $C_{p}$ the heat capacity at constant pressure and $k$ the thermal conductivity. $Q$ was a heat source or a heat sink by chemical reaction. For simplicity, $Q$ was assumed to be zero. The interpolation of convective term by $\varphi_{1}$ was to ensure that the convection is limited in gas phase and diffusive interface. The density and heat capacity of the gaseous phase and solid phase differ greatly. Details of the derivation and interpretation can be found in our previous works [30, 33, 34].

In summary, the multiphase field model consists of the following coupled components: phase-field eqns. (13), mass transport eqns. (14), fluid motion eqns. (15) and (16) as well as heat transport eqns. (17).

\subsection{Finite element implementation for multiphase field model}

The usual finite element analysis would proceed from the selection of a mesh and basis to the generation of a solution to an accuracy appraisal and analysis. Generally speaking, with more elements in a mesh, the solution is more precise. This is because there are more nodes that are available for calculating response and thus the solution is more precise, and more elements mean smaller elements so discretization error is minimized. Accuracy appraisals typically require the generation of a second solution on a finer mesh or with a higher order polynominal and a comparison of the two solutions [36-38]. The experience demanding general FEM 
causes trouble for the complex problem, thus scientists are focusing on the development of a more intelligent method-adaptive FEM. Adaptive procedure try to automatically refine, coarsen or relocate a mesh or adjust the basis to achieve a solution having a specified accuracy in an optimal fashion [39-42]. All adaptive techniques revolve around the same algorithmic flow of the program:

1. create an initial coarse mesh,

2. solve the system of equations on the mesh (using FEM or FVM or BEM),

3. estimate the error at either each node (for node-based adaptation techniques) or each element (for element-based adaptation techniques) or each edge (for edge-based adaptation techniques),

4. adapt the grid based on the adaptivity criteria generated based on the error estimation, and

4. interpolate the previous solution over the new mesh and repeat from the second step until end of solution.

Let $\Omega$ be a continuous and smooth domain and $R^{d}(\mathrm{~d}=1,2$ or 3$)$ be its piecewise polygonal boundary and is the initial triangulation of the domain. Then, for any triangle $T \in \tau$ as shown in Fig. 3, the following statements are true:

1. its included angles are $\alpha, \beta, \gamma$, where $\alpha \geq \beta \geq \gamma$ and

2. its edges are $l_{1}, l_{2}, l_{3}$, where their lengths, $l_{1} \geq l_{2} \geq l_{3}$.

Additionally, a set of operations on the mesh are defined as follows:

1. A refinement operation on a node $\mathrm{N}$ of the mesh is defined as $f_{\mathrm{R}}\left(N, \tau_{\mathrm{i}}\right)=\tau_{\mathrm{i}+1}$ where $\left(\tau_{0}, \ldots\right.$ $\tau_{\mathrm{i}} \ldots \tau_{\mathrm{n}}$ ) form a set of nested triangulations where $\tau_{\mathrm{i}}$ is obtained by a local refinement of $\tau_{\mathrm{i}-1}$.

2. A refinement operation on a triangle $\mathrm{T}$ of the mesh is also defined as $f_{\mathrm{R}}\left(T, \tau_{\mathrm{i}}\right)=\tau_{\mathrm{i}+1}$.

3. A coarsening operation at a node $\mathrm{N}$ or a triangle $\mathrm{T}$ is defined as $f_{\mathrm{C}}\left(T, \tau_{\mathrm{i}}\right)=\tau_{\mathrm{i}-1}$ and $f_{\mathrm{C}}$ $\left(T, \tau_{\mathrm{i}}\right)=\tau_{\mathrm{i}-1}$ respectively.

With these definitions, the adaptation procedures were developed for this work, details of which can be found in our previous communications [40].

With appropriate initial and boundary conditions, the multiphase field model was implemented on the geometric model as shown in Fig. 4 for unidirectional fibre-reinforced composite. For 3D cases, the one-fibre or the multifibres model can be used. Due to the

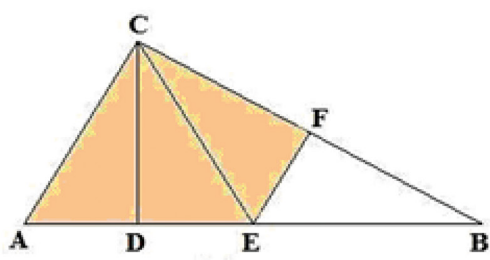

(a)

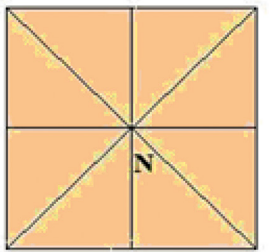

(b)

Figure 3: Stable molecules around vertex C (a) and N (b) [41]. 
(a)

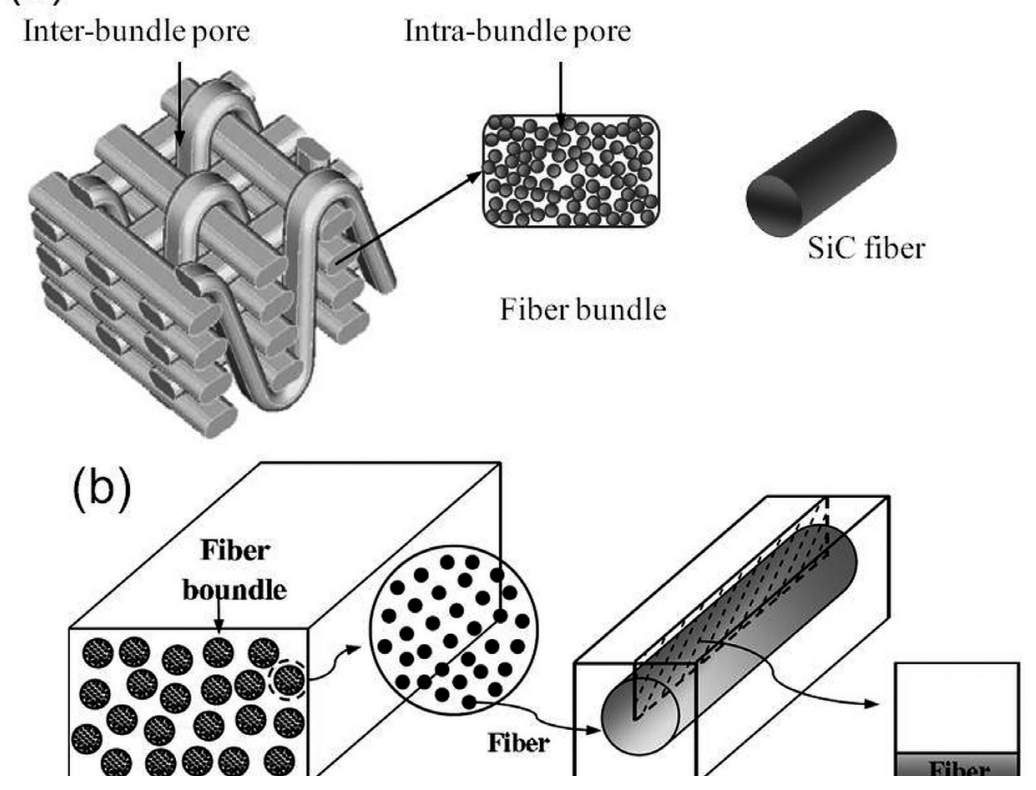

Figure 4: Schematic illustrations of (a) fibre perform and (b) unidirectional fibre-reinforced substrates.

symmetry along the radial section of the fibre, this $3 \mathrm{D}$ model often can be reduced to a $2 \mathrm{D}$ model. The numerical discretization for the multiphase field formulation consists of two parts: temporal discretization and spatial discretization. In this work, we use the implicit Euler finite difference approximation for temporal discretization and Galerkin weighted residual method for spatial discretization. The numerical simulations were performed based on the software 'COMSOL Multiphysics' with the relative tolerance le-2 and le- 4 . The high-performance computing clusters 'InstitutsCluster' in Karlsruhe Institute of Technology performed the distributed parallelization calculation (1,048,944 DOF). Each node contains two Quad-core Intel Xeon processors with clock speed of $2.667 \mathrm{GHz}$ with $16 \mathrm{~GB}$ of main memory and four local disks (250 GB each). The MATLAB ${ }^{\circledR}$ script for parallelized nonoverlapping domain decomposition (DD) was integrated into COMSOL software interface LiveLink $^{\mathrm{TM}}$ [27]. The simulation of 3D SiC deposition by parallel performance was determined by solver. It indicates that the best balance between computation load and communication overhead was to choose CPU number as 6-8. Details of finite element implication can be found in our previous works $[27,41]$ in addition to non-overlapping DD, algorithm and error estimation.

\section{RESULTS AND DISCUSSION}

\subsection{Numerical simulation results}

The model parameters used during numerical simulation are listed in Table 1. Simulation results of microstructural evolution during SiC deposition are shown in Fig. 5. The growth of solid phase near the precursor inlet side was much faster than that of outlet side, which 
Table 1: Parameters used in the model [30].

\begin{tabular}{lc}
\hline Parameter & Value \\
\hline$\in_{\mathrm{ij}}\left(\mathrm{Jm}^{-1}\right)^{1 / 2}$ & $5.8 e-4$ \\
$P(\mathrm{~Pa})$ & $1.01325 e 5$ \\
$T(\mathrm{~K})$ & 1123 \\
$\rho_{\mathrm{g}}\left(\mathrm{kg} \mathrm{m}^{-3}\right)$ & 0.167 \\
$D_{\mathrm{CH} 3 \mathrm{SiCl} 3, \mathrm{H} 2}\left(\mathrm{~m}^{2} \mathrm{~s}^{-1}\right)$ & $7.26 e-4$ \\
$\gamma_{\mathrm{H} 2}$ & 0.9 \\
$l_{2 D}(\mathrm{~m})$ & $1.5 e-5$ \\
$\eta_{\mathrm{s}}(\mathrm{Pa} . \mathrm{s})$ & 2.6 \\
$W_{i j}\left(\mathrm{~J} \mathrm{~m}{ }^{-1}\right)$ & $1.32 e-7$ \\
$M_{i j}\left(\mathrm{~m} \mathrm{~s}^{-1}\right)$ & $2.09 e-7$ \\
$u_{x}\left(\mathrm{~m} \mathrm{~s}^{-1}\right)$ & $3 e-2$ \\
$\rho_{\mathrm{s}}\left(\mathrm{Kg} . \mathrm{m}^{-3}\right)$ & 3200.0 \\
$D_{\mathrm{HCl}, \mathrm{H} 2}\left(\mathrm{~m}^{2} \mathrm{~s}^{-1}\right)$ & $1.47 e-3$ \\
$\gamma_{\mathrm{MTS}}$ & 0.1 \\
$L_{3 D}(\mathrm{~m})$ & $1 e-5$ \\
$\eta_{\mathrm{g}}(\mathrm{Pa} \mathrm{s})$ & $2.62 e-5$ \\
\hline
\end{tabular}

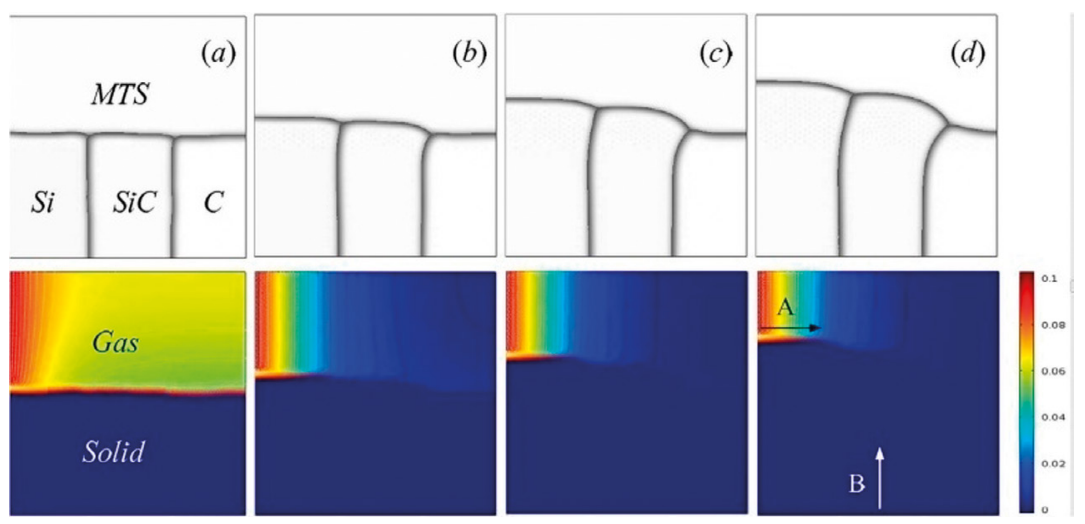

Figure 5: Phase-field evolution of microstructure and gas composition distribution at scaled time: (a) $t=0$, (b) $t=0.5$, (c) $t=1.1$ and (d) $t=1.5$ [30].

implies the risk of blockage of the premature pores. Also we can find that the $\mathrm{C}$ (graphite) phase tends to be eliminated by SiC phase due to its overgrowth. This was in line with experiments $[27,42]$ that only co-deposition of $\mathrm{Si}(\mathrm{s})$ and $\mathrm{SiC}(\mathrm{s})$ exists while $\mathrm{C}$ (graphite) phase was absent under high ratios of $\mathrm{H}_{2}$ to MTS $(>104)$. As deposition time progresses, the concentration of MTS near the inlet side was much higher than that of the rest, and this distribution favours the growth of the solid phase near the inlet side. The concentration of MTS at sections A and B at different time-step moments was shown in Fig. 6. The step increasing in the curves along section B indicates the location of gas/solid interface, with the left part in solid phase and the right part in gas phase. This shows that as time progresses, 


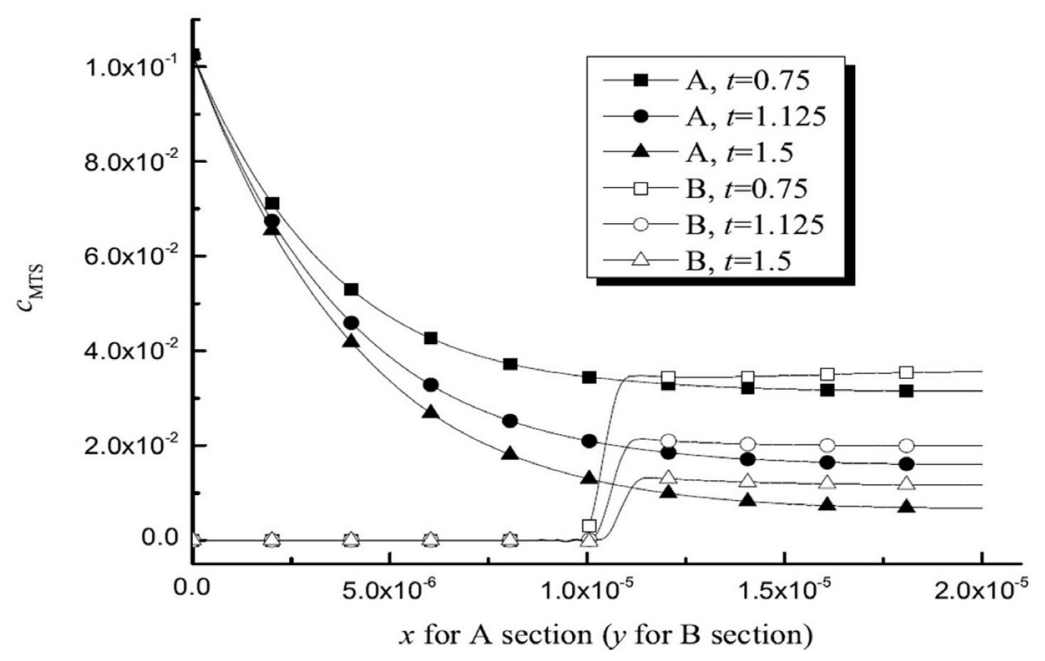

Figure 6: Time-dependent concentration of MTS ( $\left.c_{\mathrm{MTS}}\right)$ at sections A and B [30].

MTS concentration $\left(c_{\mathrm{MTS}}\right)$ along these sections decreases. The gradient decreasing along section A was obvious, which was mainly caused by chemical reaction. However, along section B there barely exist any changes in MTS concentration as diffusion was weak compared with that caused by chemical reaction.

By changing the reaction diffusion equation, the effect of fluid flow and chemical reaction on concentration change of MTS was investigated. Three cases were set up: (a) only diffusion was considered, (b) constant fluid flow was considered in mass transport equation based on case (a) and (c) chemical reaction in mass transport equation was considered based on case (a). The simulation shows that the fluid flow in case of (b) changes MTS concentration field as in case (a) and tends to reduce the concentration gradient as shown in Fig. 7.

This homogenization of MTS was in favour of even deposition to reduce the potential pore blockages which cause the porosity in matrix. After chemical reaction was introduced into the diffusion equation as in case (c), the concentration at nearby inlet side quickly decreased to a small value compared with nearby outlet side of the reactor, which indicates that MTS was highly reactive and prone to decompose. As the decomposition of MTS was highly temperature dependent, the thermo-gradient CVI (TGCVI) was employed in practice to improve the $\mathrm{SiC}$ deposition environment. From this simulation, it can be concluded that the fluid flow was in favour of infiltration conditions and single-phase $\mathrm{SiC}$ was deposited. Figure 8a shows the growth of multi-SiC grains with different initial seed sizes. It was observed that as deposition proceeds, the $\mathrm{SiC}$ grains with small size tend to be eliminated by those surrounding grains due to competitive growth. The 3D simulation of $\mathrm{SiC}$ grains growth with uniform seeds was shown in Fig. 8b. The SiC deposition on SiC fibre surface under the constant fluid was simulated as shown in Fig. 9. It clearly shows that the premature pore blockage occurs with narrow entrance and wide end.

During TGCVI process, a faster SiC deposition occurs near the outlet side (hot region) compared with an inlet side (cold region) as shown in Fig. 10. In this figure, the marked line was the solid-gas interface between deposited SiC matrix (downside area) on fibre and gaseous phase (upside area). Therefore, the temperature gradient helps to prevent the formation of pore blockage at nearby inlet side in which the fibre was exposed to precursor gases in the 


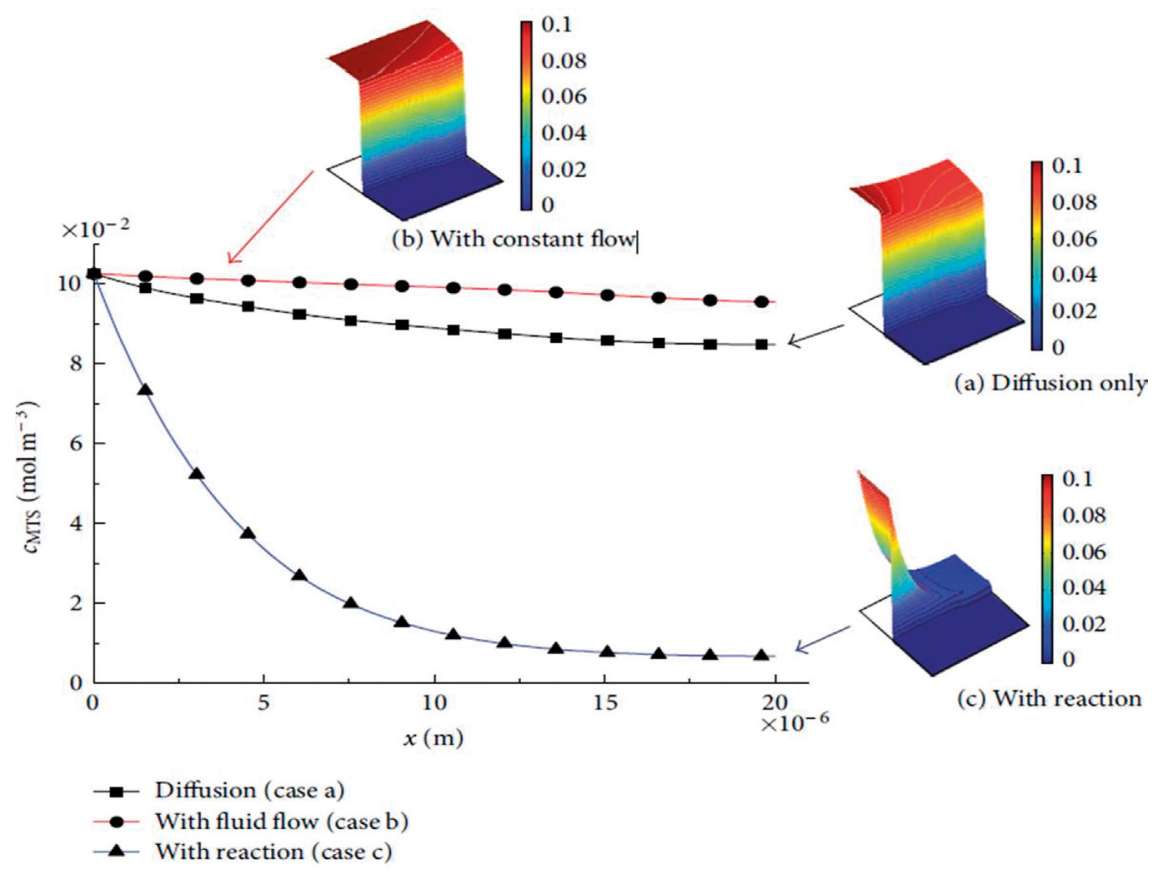

Figure 7: The effect of fluid and chemical reaction on concentration of MTS $\left(c_{\text {MTS }}\right)$ [30].
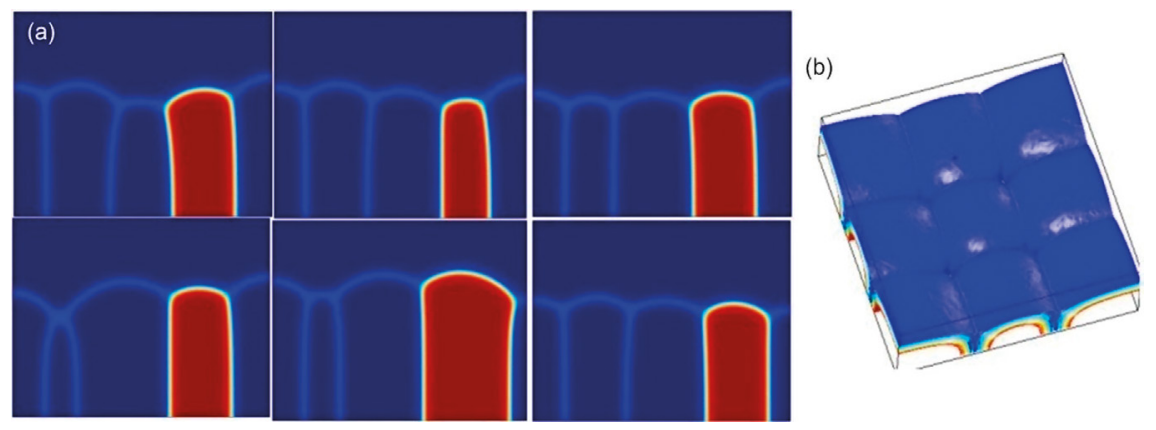

Figure 8: Columnar growth: (a) $\mathrm{SiC}$ deposited as grains and (b) $\mathrm{SiC}$ grain in 3D [30].
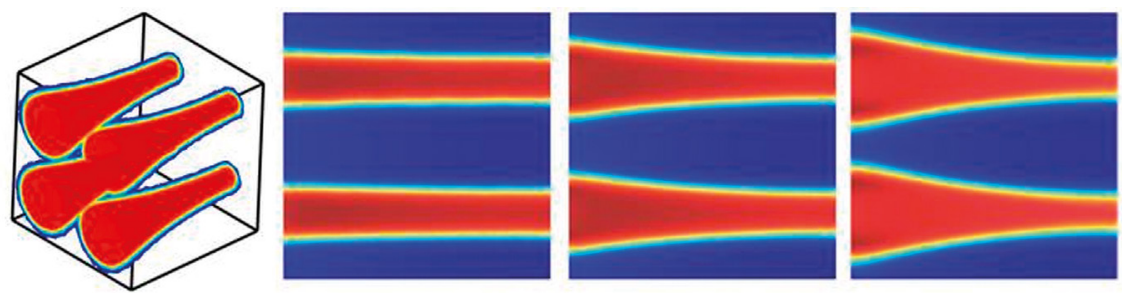

Figure 9: Blockage formation during $\mathrm{SiC}$ fibre deposited with $\mathrm{SiC}$ [30]. 


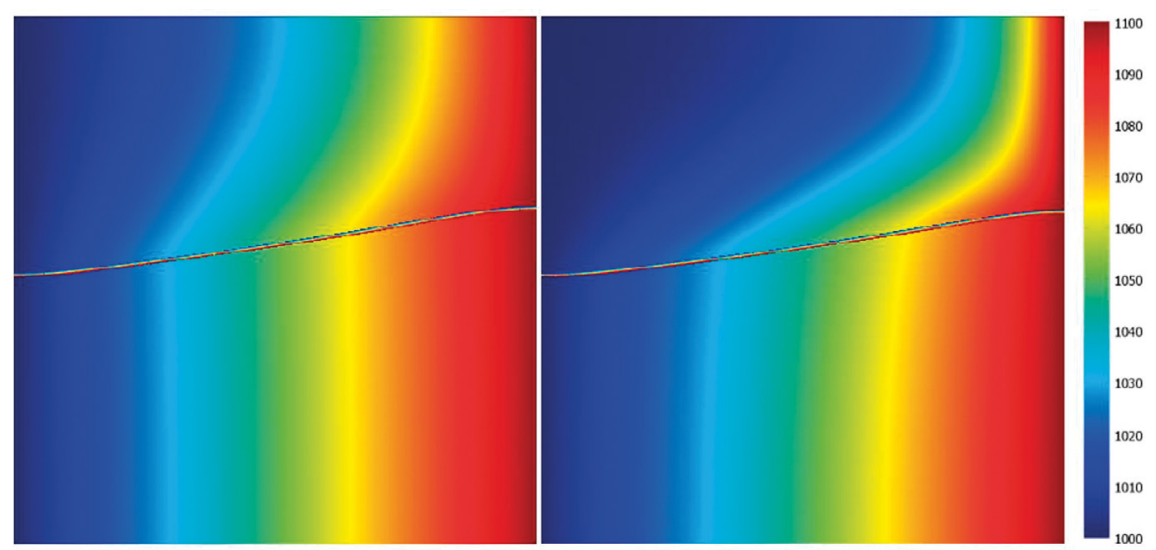

Figure 10: (a) Temperature field and (b) temperature field under accelerated gas flow during TGCVI process [27].

low-temperature region first. Due to significant difference in thermal conductivities of gaseous and solid phase (fibre and matrix), the temperature distribution shows a transition area along the deposition surface. In addition, the temperature distribution at gaseous phase was also affected by gas fluid. Comparing Fig. 10a and b, it could be concluded that the faster the gas from cold inlet side to hot wall, the steeper the temperature gradient nearby outlet side.

Surface coverage and change of deposition rate at isothermal temperature $T(1000-1373 \mathrm{~K})$ was shown in Fig. 11. Details of the standard numerical computations to find the real roots of the corresponding equations of the system can be found in our earlier communications [30, 33, 34]. For appropriate values of $T$, the system has three branches of solutions (Fig. 11). It clearly shows that the $(\mathrm{Si}+\mathrm{C})$ co-deposition rate and the surface coverage of adsorbed $\mathrm{Si}$ and C- precursor species present multiplicity of steady states. It is also not difficult to find that the intermediate sigmoid branch is unstable. The unstable equilibrium branch connects the high-temperature branch with the lower one, leading to relay-type hysteresis behaviour. Further calculations exhibits high deposition rates due to deposition of $\mathrm{SiC}$ formed by bi-molecular cross reactions between adsorbed $\mathrm{Si}$ - and $\mathrm{C}$ - precursor species, while lower deposition rates at lower temperatures consists of formation of silicon and carbon from dechlorination and dehydrogenation of adsorbed Si- and C- precursor species, respectively, as shown schematically in Fig. 12. Using scanning electron microscopy (SEM), X-ray diffraction and energy dispersive spectroscopy (EDS), a sharp change in the composition of deposit coinciding with the abrupt change in the deposition rate hysteresis regime was reported by Papasouliotis and Sotirchos [43] and Zhang and Hüttinger [24]. Deposition obtained at high deposition rates consists of polycrystalline $\beta$-SiC, whereas Papasouliotis and Sotirchos [43] confirmed that deposits formed at the low reactivity branch consist of amorphous carbon and Zhang and Hüttinger [24] detected only free Si within the same temperature region. This should be due to the different $\mathrm{MTS} / \mathrm{H}_{2}$ ratios (the former used a higher ratio of 10 , while the latter used a smaller ratio of 4) employed by the researchers.

To understand the influence of temperature on gas-phase composition by using this multistep reaction mechanism, a plug reactor model is proposed to simulate the present experiments $[16,18,19]$. Under isothermal/isobaric conditions, the effect of temperature on gas-phase 


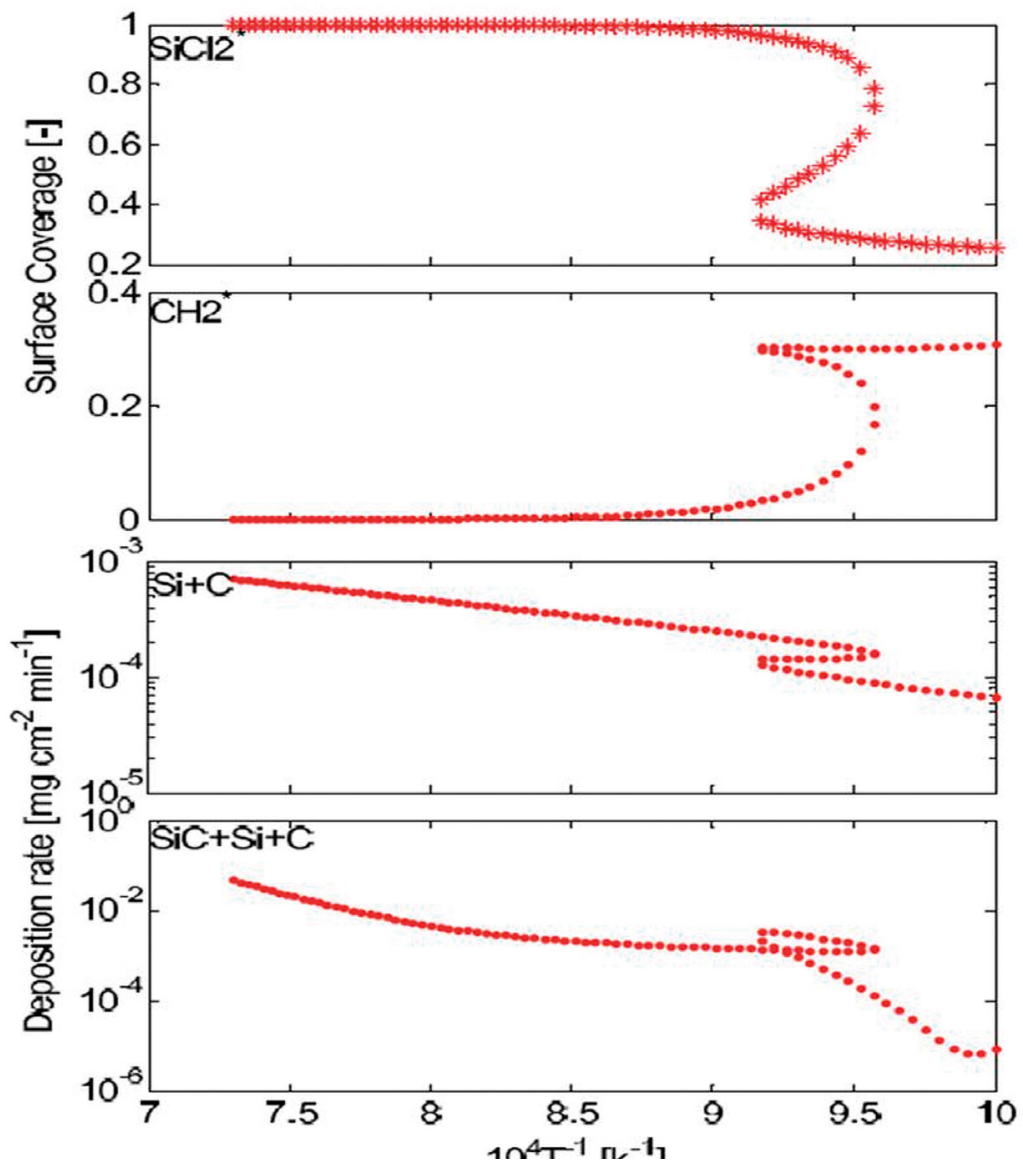

Figure 11: Surface coverage and deposition rate of $\mathrm{SiC}$ as a function of temperature [27].

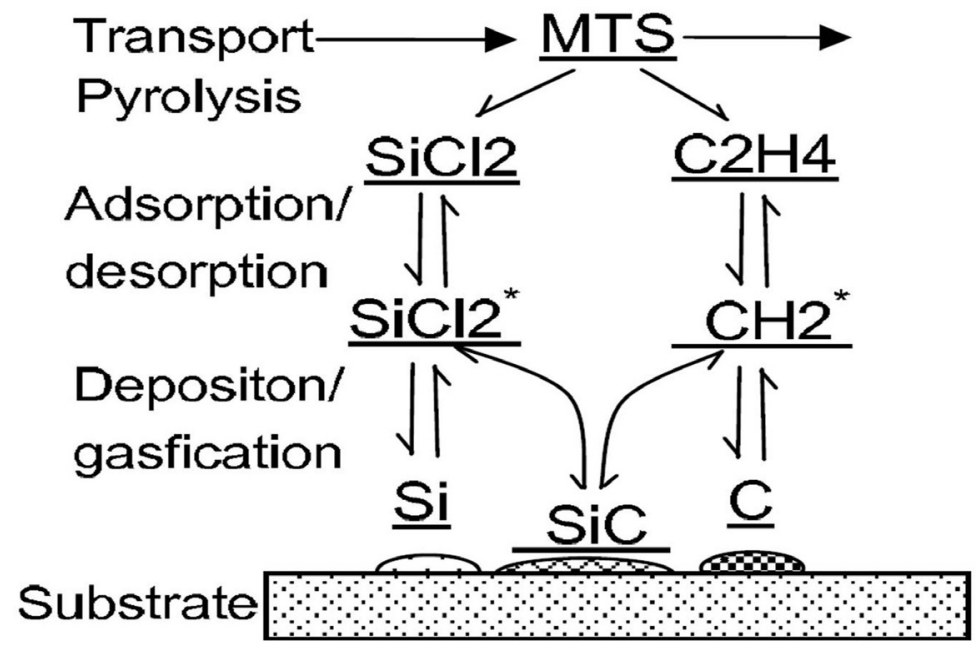

Figure 12: Reaction scheme for MTS pyrolysis and deposition [27]. 

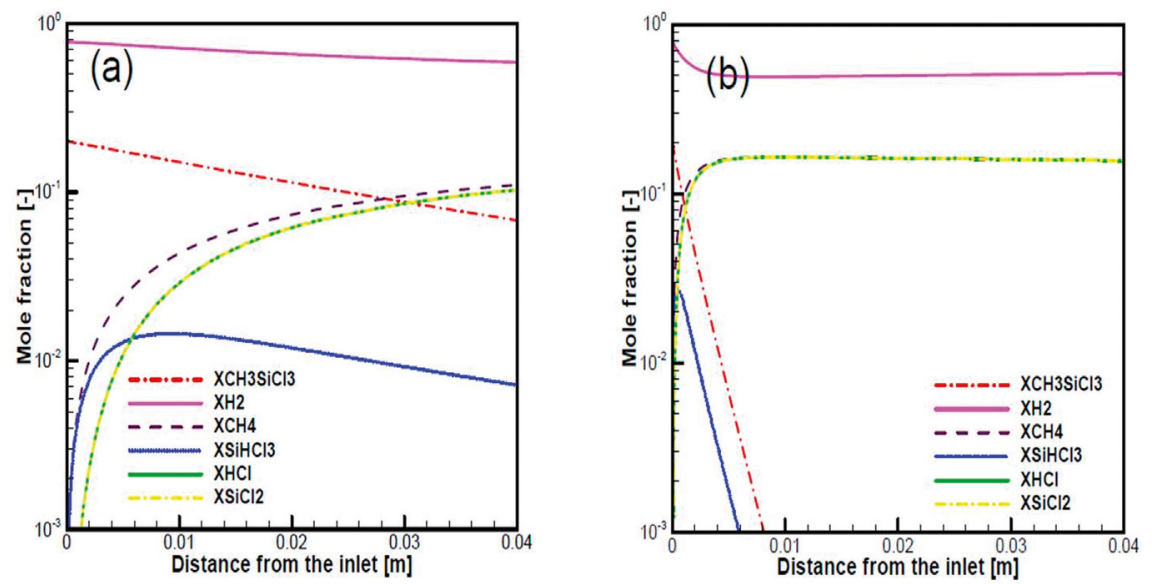

Figure 13: Gas-phase compositions vs. distance from the inlet $\left(\mathrm{H}_{2} / \mathrm{MTS}=4\right)$ at (a) $850^{\circ} \mathrm{C}$ and (b) $950^{\circ} \mathrm{C}$ [27].

composition is shown in Fig. 13 along the distance from the inlet at a $\mathrm{H}_{2} / \mathrm{MTS}$ ratio of 4 with various isothermal temperatures of the reactor.

A significant decrease in MTS concentration was predicted with increasing temperature, as well as concentration of $\mathrm{CH}_{4}, \mathrm{SiHCl}_{3}$ and $\mathrm{HCl}$. At a temperature of $850^{\circ} \mathrm{C}$, the mole fraction of MTS approaches less than $10 \%$ at the end of substrate. Due to high $\mathrm{H}_{2} / \mathrm{MTS}$ ratio in the reactor feed gas, the mole fraction of hydrogen changes by a small amount along the axial direction of the reactor, implying its lesser effect on gas-phase composition. With the temperature approaching $950^{\circ} \mathrm{C}$, MTS was nearly decomposed. $\mathrm{SiCl}_{2}$ and $\mathrm{SiCl}_{4}$ were exhibiting relatively stable mole fractions at $950^{\circ} \mathrm{C}$ and were the dominant intermediate species, while $\mathrm{CH}_{4}$ was showing higher temperature stability. As is well known, $\mathrm{HCl}$ is one of the main by-products of CVI of SiC from MTS. However, only a small mole fraction of $\mathrm{HCl}$ was predicted during the pyrolysis of MTS at temperatures below $950{ }^{\circ} \mathrm{C}$. As shown in Fig. 13, the formation of $\mathrm{HCl}$ is always accompanied by the formation of $\mathrm{SiHCl}_{3}$ along the substrate axial direction and exhibits higher fraction than that of $\mathrm{SiHCl}_{3}$ due to uni-molecular dissociation reaction of $\mathrm{SiHCl}_{3}$ on the formation of $\mathrm{HCl}$. Sensitivity and reaction rate analysis will be among the objectives of our future studies in order to figure out the key steps of MTS pyrolysis and the formation of dominant species in the gas phase.

\subsection{Experimental investigation}

The temperature distribution within the reactor during TGCVI process is shown in Fig. 14. Densification of the $\mathrm{SiC}$ fibre felt was performed with a total pressure of $8 \mathrm{kPa}$, a total flow rate of $330 \mathrm{ml} / \mathrm{min}$, and a $\mathrm{H}_{2} / \mathrm{MTS}$ molar ratio of 10 .

The residence time of the gas phase in the reactor chamber is $<1 \mathrm{~s}$. For each run, the densification duration was about $10 \mathrm{~h}$. The initial temperature profile consists of two branches: one linear distribution within the fibre and another one linear distribution within the gaseous gap. However, with increasing densification time, the deposition front moves very slowly. Moreover, the temperature profile was divided into three sections and the temperature gradient was increasing with the movement of the deposition front. The porosity of densified 


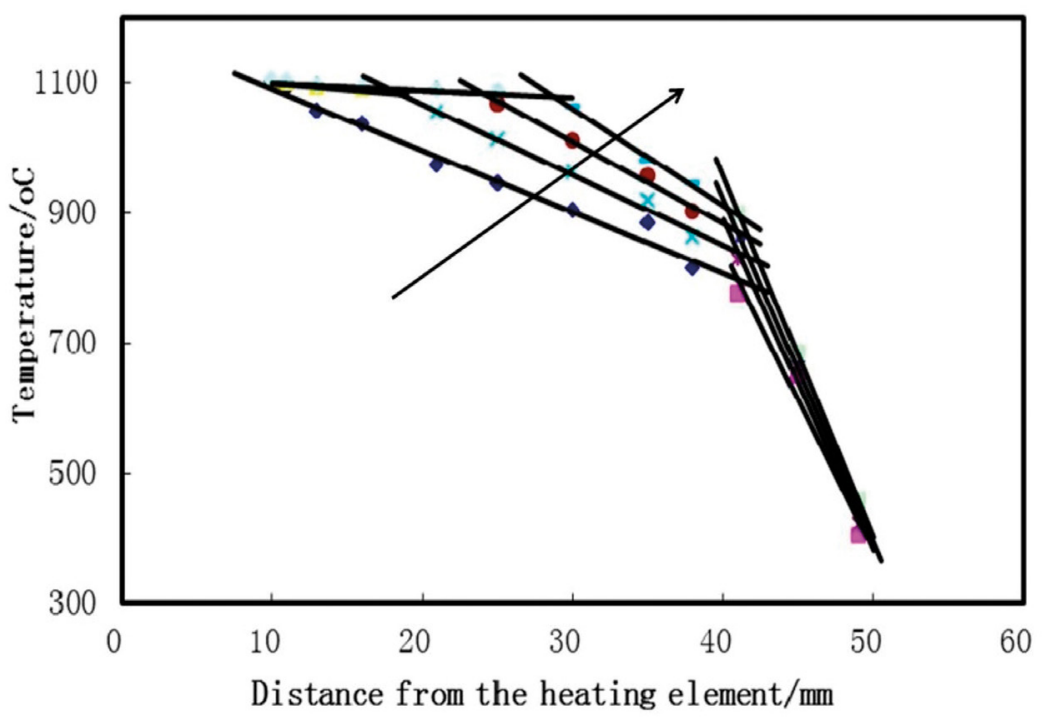

Figure 14: Temperature distribution within the reactor (solid lines are linear fitting of experimental data points) [27].

region reaches $15 \%$, implying that a higher temperature gradient was needed for a better densification degree.

Two subsequent deposition experiments of about $3 \mathrm{~h}$ were performed for each operating temperature $\left(800,850,900,950,1000,1050\right.$ and $\left.1100^{\circ} \mathrm{C}\right)$ under $\mathrm{H}_{2} / \mathrm{MTS}$ mole ratio of 4 or 8. The steady-state deposition rate per surface area was determined as a function of the length of the substrate. The effect of temperature on the deposition rate of $\mathrm{SiC}$ (with $\mathrm{H}_{2} /$ MTS =4), as shown in Fig. 15, was presented in Arrhenius plot coordinates, i.e., as the surface related deposition rate vs. $1 / \mathrm{T}$, with $\mathrm{T}$ being the absolute temperature in the reactor and three regimes namely, I, II and III were observed.

Regime-I extends from 800 to $850^{\circ} \mathrm{C}$, the steady-state deposition rate differs by about two orders of magnitude. From temperatures above the upper limit of regime-I, regime-II of a relatively even deposition rate exists with an inconspicuous maxima at $900^{\circ} \mathrm{C}$. From temperatures above the upper limit of regime-II, the deposition rate increases monotonically and proceeds at a significant rate varying from 0.002 to $0.1 \mathrm{mg} \mathrm{cm}{ }^{2}$. $\mathrm{min}^{1}$. The significant variation of $\mathrm{SiC}$ deposition rates within regime-I was already studied with a hysteresis model by Papasouliotis and Sotirchos [43] and Sotirchos and Papasouliotis [44]. The hysteresis behaviour on temperature within regime-I was a characteristic signature of steady-state multiplicity of the ignition-extinction phenomena appearing in the catalytic reactions, the location of which depends on the exact processing parameters such as residence time, pressure and substrate position [44]. Further investigation shows that the Langmuir-Hinshelwood mechanism [43] of intermediate species in gas phase as well as the bimolecular reactions of various adsorbed species on the surface can be used to explain the hysteresis behaviour. This clearly shows that the $(\mathrm{Si}+\mathrm{C})$ co-deposition rate and the surface coverage of adsorbed $\mathrm{Si}$ - and $\mathrm{C}$ - precursor species present multiplicity of which the sigmoid part corresponds to the regime-I as already predicted by numerical simulation results as described in Section 4.1 (Fig. 11). The regimes II and III in Fig. 15 have also 


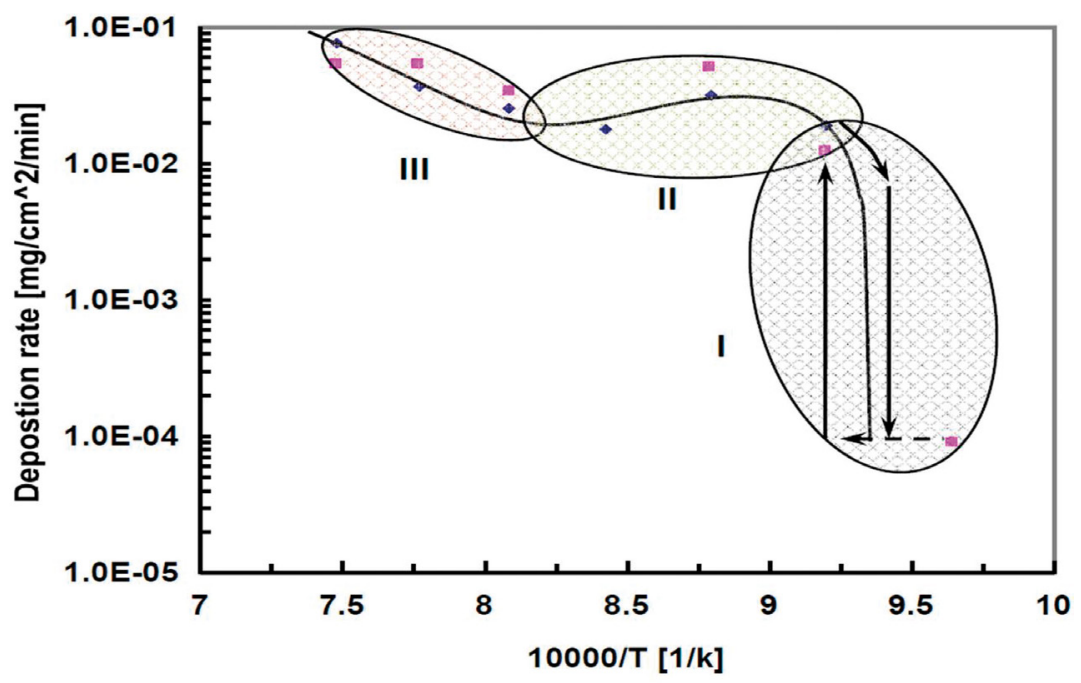

Figure 15: Surface-related deposition rate $\left(\mathrm{H}_{2} / \mathrm{MTS}=4\right)$ as a function of the reciprocal temperature [27].

been predicted by this surface reaction model (Fig. 11) thus confirming the agreement of the simulation results with the experimental data.

Microstructure morphology and composition of the composites using SEM, EDS and electron probe microanalysis (EPMA) are foreseen and recommended as a further study of this current investigation.

\section{CONCLUSIONS}

The multiphase field model was presented in this research to predict the microstructural evolution through simulation during the CVI process of $\mathrm{SiC} / \mathrm{SiC}$ composite fabrication and was verified by experimental results. By this multiphase field model, multi-solid phase co-deposition behaviour was described instead of single $\mathrm{SiC}$ deposition. The model consists of Ginzburg-Landau phase-field equations, mass/heat/fluid transport equations and the modified Navier-stokes equations. Both homogeneous process and heterogeneous process were included in the model through process intensities. The microstructural evolution of the preferential co-deposition of $\mathrm{Si}(\mathrm{s}), \mathrm{SiC}(\mathrm{s})$ was reproduced with kinetic inhibition of $\mathrm{C}$ (graphite) phase, which was in accordance with experimental research. Meanwhile, the potential risk of blockage of the premature pores during CVI process was predicted. Simulations show that the concentration of MTS was homogenized by fluid flow which was in favour of the even deposition, and this concentration field was mainly dominated by the chemical reaction. The multi SiC-grains deposition simulation reproduces the competitive growth mechanism during the coarsening process. The simulation found that thermal gradient helps to prevent the formation of pore blockage and the gradient at gaseous phase near the outlet side will be enhanced by accelerated gas flow. With the help of experiment results, together with simulation outcomes, a heterogeneous surface reaction model was proposed, which successfully predicts the rate behaviour with the temperature ranging from 800 to $1100^{\circ} \mathrm{C}$. High deposition rates were ascribed to the deposition of $\mathrm{SiC}$ formed by bi-molecular cross reactions between adsorbed $\mathrm{Si}$ - and $\mathrm{C}$ - precursor species, while lower deposition rates at lower 
temperatures consist of formation of silicon and carbon from dechlorination and dehydrogenation adsorbed Si- and C- precursor species, respectively. So far, to the best of authors' knowledge, there has not been a study to combine both numerical and experimental investigation of CVI (gas route) process of $\mathrm{SiC} / \mathrm{SiC}$ composites with MTS as the precursor (by pyrolysis).

\section{ACKNOWLEDGEMENT}

The financial support by the German Research Foundation (DFG Schn 245/31-1/2) is gratefully acknowledged.

\section{REFERENCES}

[1] Leuchs, M., Chemical vapour infiltration processes for ceramic matrix composites: manufacturing properties (Chapter 9), Ceramic matrix composites, ed. W. Krenkel, Wiley-Weinheim, Germany, pp. 141-164, 2008.

[2] Golecki, I., Rapid vapour phase densification of refractory composites. Materials Science and Engineering R, 37, pp. 118-124, 1997. doi: http://dx.doi.org/10.1016/ s0927-796x(97)00003-x

[3] Lamon, J., Chemical vapour infiltrated $\mathrm{SiC} / \mathrm{SiC}$ composites (CVI SiC/SiC), Handbook of ceramic composites, ed. N. Bansal, Kluwer Academic Publishers, Boston, pp. 55-76, 2005. doi: http://dx.doi.org/10.1007/0-387-23986-3_3

[4] Delhaes, P., Review - chemical vapour deposition and infiltration processes of carbon materials, Carbon, 40(5), pp. 641-657, 2002. doi: http://dx.doi.org/10.1016/s00086223(01)00195-6

[5] Amirthan, G., Udayakumar, A., Bhanu, P.V.V. \& Balasubramanian, M., Properties of Si/ $\mathrm{SiC}$ ceramic composite subjected to chemical vapour infiltration. Ceramic International, 35(7), pp. 2601-2607, 2009. doi: http://dx.doi.org/10.1016/j.ceramint.2009.02.022

[6] Naslain, R.R., Langlais, F., \& Fedou, R., The CVI - processing of ceramic matrix composites. Journal of Physics, 50(C5), pp. 191-207, 1989. doi: http://dx.doi.org/10.1051/ jphyscol:1989526

[7] Naslain, R.R., Material design and processing of high temperature ceramic matrix composites: state of the art and future trends, Advance Composite Materials, 8(1), pp. 3-16, 1999. doi: http://dx.doi.org/10.1163/156855199x00029

[8] Buckley J.D., Carbon-carbon, an overview. American Ceramic Society Bulletin, 67(2), pp. 364-368, 1988.

[9] Manocha, L.M. \& Pande, R., Growth of carbon nanotubes on silicon carbide fabric as reinforcement for SiC/C composites. Journal of Nanoscience and Nanotechnology, 10(6), pp. 3822-3827, 2010. doi: http://dx.doi.org/10.1166/jnn.2010.1968

[10] Sauder, C., Brusson, A. \& Lamon, J, Mechanical properties of Hi-NicalonS and SA3 fibre reinforced $\mathrm{SiC} / \mathrm{SiC}$ minicomposites. International Journal of Applied Ceramic Technology, 7(3), pp. 291-303, 2010. doi: http://dx.doi.org/10.1002/9780470456361. ch9

[11] Yan, Z.Q., Chen, F., Xiong, X., Xiao, P., Zhang, H.B. \& Huang, B.Y., Oxidation behaviour of CVI, MSI and CVI+MSI C/SiC composites. Transactions of Nonferrous Metals Society of China, 20(4), pp. 590-596, 2010. doi: http://dx.doi.org/10.1016/s10036326(09)60183-7

[12] Petrak, D.R., Ceramic matrices, Composites, ASM Handbook, ed. D.B. Miracle \& S.L. Donaldson, Vol. 21, ASM International, USA, pp. 160-163, 2001. 
[13] Bang, K.-H., Chung, G.-Y. \& Koo, H.-H., Preparation of C/C composites by the chemical vapours infiltration (CVI) of propane pyrolysis. Korean Journal of Chemical Engineering, 28(1), pp. 272-278 2011. doi: http://dx.doi.org/10.1007/s11814-010-0352-y

[14] Guan, K., Laifei, C., Qingfeng, Z., Hui, L., Shanhua, L., Jianping, L. \& Litong, Z., Prediction of permeability for chemical vapour infiltration. Journal of the American Ceramic Society, 96(8), pp. 2445-2453, 2010. doi: http://dx.doi.org/10.1111/jace.12456

[15] Pedersen, H., Leone, S., Henry, A., Beyer, F.C., Darakchieva, V. \& Janzén, E., Very high growth rate of $4 \mathrm{H}-\mathrm{SiC}$ epilayers using the chlorinated precursor methyltrichlorosilane (MTS). Journal of Crystal Growth, 307(2), pp. 334-340, 2007. doi: http://dx.doi. org/10.1016/j.jcrysgro.2007.07.002

[16] Schnack, E., Wang, F.W. \& Li, A.J., Phase-field model for the chemical vapour infiltration of silicon carbide. Journal of the Electrochemical Society, 157(7), pp. 377-386, 2010. doi: http://dx.doi.org/10.1149/1.3409493

[17] Kulik, V.I., Kulik, A.V., Ramm, M.S. \& Makarov, Y.N., Modelling of SiC-matrix composite formation by isothermal chemical vapour infiltration. Journal of Crystal Growth, 266(1-3), pp. 333-339, 2004. doi: http://dx.doi.org/10.1016/j.jcrysgro.2004.02.063

[18] Zhu, Y., Schnack, E. \& Li, A.J., Multiphase field modelling chemical vapour infiltration of SiC/SiC composite. Proceedings in Applied Mathematics and Mechanics, 11(1), pp. 453-454, 2011. doi: http://dx.doi.org/10.1002/pamm.201110218

[19] Zhu, Y. \& Schnack, E., Modelling manufacture process of light weight SiC/SiC composites. Proceedings in International Symposium on Advances in Applied Mechanics and Modern Information Technology, MIT11, pp. 283-287, 2011.

[20] Barbato, A. \& Cavallotti, C., Challenges of introducing quantitative elementary reactions in multiscale models of thin film deposition. Physica Status Solidi (B), 247(9), pp. 2127-2146, 2010. doi: http://dx.doi.org/10.1002/pssb.200945454

[21] Kulik, V.I., Kulik, A.V., Ramm, M.S., Nilov, A.S. \& Bogdanov, M.V., Two-dimensional model of conjugate heat and mass transport in the isothermal chemical vapour infiltration of 3D preform by SiC matrix. Silicon Carbide and Related Materials, 483, pp. 245-250, 2005. doi: http://dx.doi.org/10.4028/www.scientific.net/msf.483-485.245

[22] Vignoles, G.L., Modelling of the CVI processes. Advances in Science and Technology, 50, pp. 97-106, 2006. doi: http://dx.doi.org/10.4028/www.scientific.net/ast.50.97

[23] Zhu, Y., Schnack, E. \& Iancu, G., Modelling chemical vapour infiltration of SiC composites. Proceedings in TMCE 2012, 2, pp. 787-796, 2012.

[24] Zhang, W.G. \& Hüttinger, G.K., Chemical vapour deposition of SiC from ethyltrichlorosilane, part-II: composition of the gas phase and the deposit. Advanced Materials of CVD, 7, pp. 173-181, 2001.

[25] Allendorf, M.D. \& Melius, C.F., Theoretical study of thermochemistry of molecules in the silicon-carbon-chlorine-hydrogen system. Journal of Physical Chemistry, 97, pp. 720-728, 1993. doi: http://dx.doi.org/10.1021/j100105a031

[26] Fitzer, E. \& Kehr, D., Carbon, carbide and silicide coatings. Thin Solid Films, 39, pp. 55-57, 1976.

[27] Schnack, E., 3D simulation of the manufacturing process for composites with a SiCmatrix, Final Report-project DFG Schn245/31, Karlsruhe Institute of Technology (KIT), Germany.

[28] Chase, M.W., Nist-janaf thermochemical tables. Journal of Physical Chemistry Data, 9, pp. 1-1951, 1998.

[29] Gurvich, L.V., Veyts, I.V. \& Alcock, C.B., Thermodynamic properties of individual substances, Hemisphere Publishing, USA, 1989. 
[30] Zhu, Y. \& Schnack, E., Numerical modelling chemical vapour infiltration of SiC composites. Journal of Chemistry, 2013, pp. 1-11, 2013. doi: http://dx.doi.org/ $10.1155 / 2013 / 836187$

[31] Eggleston, J.J., McFaddenand, G.B. \&. Voorhees, P.W., A phase-field model for highly anisotropic interfacial energy. Physica D, 150, pp. 91-103, 2001. doi: http://dx.doi. org/10.1016/s0167-2789(00)00222-0

[32] Schnack, E., Wang, F.W., Langhoff, T.-A. \& Li, A. J., Modelling and simulation of composites in the design process, 7th International Symposium on Tools and Methods in Competitive Engineering, 2008.

[33] Wang, F.W., Schnack, E. \& Zhu, Y., Discontinuous Galerkin solution of phase-field model in isothermal chemical vapour infiltration of SiC. Journal of Engineering Mathematics, 78(1), pp. 261-274, 2013. doi: http://dx.doi.org/10.1007/s10665-011-9494-0

[34] Zhu, Y., Schnack, E. \& Iancu, G., Microstructure simulation in isothermal chemical vapour infiltration of $\mathrm{SiC}$ composites. International Journal of Information Technology and Management, 13(2-3), pp. 202-215, 2013. doi: http://dx.doi.org/10.1504/ ijitm.2014.060303

[35] Beckermann, C., Dipers, H.J., Steinbach, I., Karma, A. \& Tong, X., Modelling melt convection in phase-field simulations of solidification. Journal of Computation Physics, 154, pp. 468-159, 1999. doi: http://dx.doi.org/10.1006/jcph.1999.6323

[36] Beck, T.L., Real-space mesh techniques in density-functional theory. Reviews of Modern Physics, 72(4), pp. 1041-1080, 2000. doi: http://dx.doi.org/10.1103/revmodphys.72.1041

[37] Benjeddou, A., Advances in piezoelectric finite element modelling of adaptive structural elements: a survey. Computers \& Structures, 76(1-3), pp. 347-363, 2000. doi: http://dx.doi.org/10.1016/s0045-7949(99)00151-0

[38] Liu, G.R. \& Gu, Y.T., A point interpolation method for two-dimensional solids. International Journal for Numerical Methods in Engineering, 50(4), pp. 937-951, 2001. doi: http://dx.doi.org/10.1002/1097-0207(20010210)50:4<937::aid-nme62>3.0.co;2-x

[39] Shenoy, V.B., Miller, R., Tadmor, E.B., Rodney, D., Phillips, R. \& Ortiz, M., An adaptive finite element approach to atomic-scale mechanics - the quasicontinuum method. Journal of the Mechanics and Physics of Solids, 47(3), pp. 611-642, 1999. doi: http:// dx.doi.org/10.1016/s0022-5096(98)00051-9

[40] Strouboulis, T., Copps, K. \& Babuska, I., The generalized finite element method. Computer Methods in Applied Mechanics and Engineering, 190(32-33), pp. 4081-4193, 2001.

[41] Gong, J., Phase-field modelling ICVI process of SiC with h-adaptive FEM, Internship Report, Karlsruhe Institute of Technology (KIT), Germany, 2010.

[42] Lazzeri, A., Composites processing methods (Chapter 9). CVI Processing of Ceramic Matrix Composites, eds. N.P. Bansal \& A.R. Boccaccini, John Wiley \& Sons, Inc., New York, NY, pp. 313-339, 2012.

[43] Papasouliotis, G.D. \& Sotirchos, S.V., Hydrogen chloride effects on the CVD of silicon carbide from methyltrichlorosilane. Chemical Vapour Deposition, 4-6, pp. 235246, 1998. doi: http://dx.doi.org/10.1002/(sici)1521-3862(199812)04:06<235::aidcvde235>3.0.co;2-r

[44] Sotirchos, S.V. \& Papasouliotis G.D., Experimental study of atmospheric pressure chemical vapour deposition of silicon carbide from methyltrichlorosilane. Journal of Materials Research, 14, pp. 3397-3409, 1999. doi: http://dx.doi.org/10.1557/ jmr.1999.0460 